\title{
Loss of Glutamatergic Pyramidal Neurons in Frontal and Temporal Cortex Resulting from Attenuation of FGFR1 Signaling Is Associated with Spontaneous Hyperactivity in Mice
}

\author{
Dana M. Shin, ${ }^{1}$ Sailaja Korada, ${ }^{1}$ Rossana Raballo, ${ }^{1}$ Cooduvalli S. Shashikant, ${ }^{2}$ Antonio Simeone, ${ }^{5}$ Jane R. Taylor, ${ }^{3}$ \\ Flora Vaccarino ${ }^{1,4}$ \\ ${ }^{1}$ Child Study Center, Departments of ${ }^{2}$ Cellular, Molecular, and Developmental Biology, ${ }^{3}$ Psychiatry, and ${ }^{4}$ Neurobiology, Yale University, New Haven, \\ Connecticut 06520, and ${ }^{5}$ Medical Research Council, King's College, London SE1 1UL, United Kingdom
}

\begin{abstract}
Fibroblast growth factor receptor (FGFR) gene products ( $F g f r 1, F g f r 2, F g f r 3$ ) are widely expressed by embryonic neural progenitor cells throughout the CNS, yet their functional role in cerebral cortical development is still unclear. To understand whether the FGF pathways play a role in cortical development, we attenuated FGFR signaling by expressing a tyrosine kinase domain-deficient Fgfrl ( $\mathrm{tFgfr} 1$ ) gene construct during embryonic brain development. Mice carrying the tFgfr 1 transgene under the control of the Otxl gene promoter have decreased thickness of the cerebral cortex in frontal and temporal areas because of decreased number of pyramidal neurons and disorganization of pyramidal cell dendritic architecture. These alterations may be, in part, attributable to decreased genesis of T-Brain1-positive early glutamatergic neurons and, in part, to a failure to maintain radial glia fibers in medial prefrontal and temporal areas of the cortical plate. No changes were detected in cortical GABAergic interneurons, including Cajal-Retzius cells or in the basal ganglia. Behaviorally, tFgfr1 transgenic mice displayed spontaneous and persistent locomotor hyperactivity that apparently was not attributable to alterations in subcortical monoaminergic systems, because transgenic animals responded to both amphetamine and guanfacine, an $\alpha 2 \mathrm{~A}$ adrenergic receptor agonist. We conclude that FGF tyrosine kinase signaling may be required for the genesis and growth of pyramidal neurons in frontal and temporal cortical areas, and that alterations in cortical development attributable to disrupted FGF signaling are critical for the inhibitory regulation of motor behavior.
\end{abstract}

Key words: FGFR; fibroblast growth factor; cerebral cortex; pyramidal neuron; radial glia; Tbr1; hyperactivity; proliferation

\section{Introduction}

In human as well as in mouse, there are 22 Fibroblast growth factor ( Fgf) genes and $4 \mathrm{Fgf}$ receptor ( Fgfr) genes, Fgfr1, Fgfr2, Fgr3, and Fgfr4 (Ornitz and Itoh, 2001). These genes are expressed earlier in development than other families of receptor tyrosine kinase genes and, in the CNS, many of them are already present at the neural plate stage. Some Fof knock-out mice have provided insight into the biological roles of Fgfs in brain development. For

Received Sept. 15, 2003; revised Jan. 4, 2004; accepted Jan. 5, 2004.

This work was supported by National Science Foundation Grant NSF0083104, National Institutes of Health Grant R01 NS37709, and the National Alliance for Research in Schizophrenia and Affective Disorders. We thank Drs. Joseph Hwang and Frank Ruddle for help in generating the transgenic mice. We are grateful to Yasushi Ohkubo and Brian Kim for performing the in situ hybridization experiments and Ayumi Ohkubo and Yuchun Zhang for technical assistance. We also thank Victoria Stewart for performing behavioral studies. We thank Robert Hevner, Masahiko Watanabe, and Nathaniel Heintz for providing us with antibodies that were integral tools in our investigation. We thank Amy F. T. Arnsten for helpful comments and suggestions regarding the behavioral experiments and members of the Vaccarino laboratory for insightful discussions.

Correspondence should be addressed to Flora Vaccarino, Child Study Center, Yale University, 230 South Frontage Road, New Haven, CT 06520. E-mail: Flora.vaccarino@yale.edu.

S. Korada's and C. S. Shashikant's present address: Department of Dairy and Animal Science, Penn State University, University Park, PA 16802.

DOI:10.1523/JNEUROSCI.5285-03.2004

Copyright $\odot 2004$ Society for Neuroscience $\quad$ 0270-6474/04/242247-12\$15.00/0 example, $F g f 2$ knock-out mice have a loss of pyramidal neurons in the anterior cerebral cortex (Vaccarino et al., 1999; Korada et al., 2002), which is because of a deficiency in neural progenitorstem cells within the dorsal ventricular zone (VZ) (Vaccarino et al., 1999; Raballo et al., 2000). In contrast, the Fgf8 gene is required for cortical patterning, as shown by overexpression and conditional lack of function experiments (Meyers et al., 1998; Fukuchi-Shimogori and Grove, 2001; Garel et al., 2003). Fgf14 knock-out mice have a histologically normal brain but exhibit severe ataxia and paroxysmal dyskinesia (Wang et al., 2002). The FGF2 protein binds to FGFR1, FGFR2, and, to a lesser extent, FGFR3, whereas the FGF8 protein binds strongly to FGFR3 and FGFR4 and weakly to FGFR1 in vitro (Ornitz et al., 1996; Chellaiah et al., 1999). Previous studies demonstrated that Fgfrl mRNA is expressed in the dorsal VZ, the primordium of the cerebral cortex (Vaccarino et al., 1999). Fgfr2 and Fgfr3 are also widely expressed throughout the cortical neuroepithelium, albeit with different regional distributions (Ragsdale and Grove, 2001). The specific role of each FGFR during cortical development is unclear.

Fgfrl knock-out mice die at gastrulation stages of embryonic development (Deng et al., 1994; Yamaguchi et al., 1994). Mice 
harboring a nonfunctional Fgfrl gene in progenitor cells of the forebrain show hypoplasia of the hippocampus (Ohkubo et al., 2003) or the olfactory bulb (Hebert et al., 2003) but no apparent change in size or patterning of the cerebral cortex. These data suggest that either FGF2 and FGF8 do not act through FGFR1 or the FGFR2 or FGFR3 proteins are able to compensate for the defect in Fgfrl gene function during cortical development.

To further investigate the FGFR signaling pathways in cortical development, we attenuated FGFR1 signaling by expressing a dominant negative Fgfrl transgene during embryonic brain development. A tyrosine kinase domain-deficient Fgfr1 (tFgfr1) gene construct was overexpressed throughout the embryonic prosencephalon by placing it under the control of the Otx1 regulatory region. The dominant negative $F g f r 1$ gene product is able to efficiently block signaling of all FGFRs when expressed in $\mathrm{Xe}$ nopus oocytes, whereas it does not affect unrelated tyrosine kinase receptors (Ueno et al., 1992; Werner et al., 1993; Robinson et al., 1995; Saffel et al., 1997).

We show that FGFR signaling is indispensable for the normal differentiation of specific regions of the cerebral cortex. Interfering with FGFR signaling during embryonic development causes decreased proliferation of neuroepithelial cells and abnormal radial glia process extension to the pial layer in the anterior and lateral regions of the cortical wall, hampering the generation of early born T-Brain-1 (TBR1)-positive neurons in these areas of the developing cortical plate (CP). This results in localized cortical atrophy, with decreased number and aberrant positioning of pyramidal neurons in the corresponding frontal and temporal regions of the neocortex. We also report that tFgfr 1 transgenic mice spontaneously develop stereotypic locomotor hyperactivity, behavior that was worsened by amphetamine and could be transiently ameliorated by the administration of guanfacine, an agent that preferentially stimulates $\alpha 2 \mathrm{~A}$ adrenergic receptors.

\section{Materials and Methods}

Generation of transgenic mice. To construct the plasmid for the production of the tFgfr 1 transgenic lines, a $\sim 5.4 \mathrm{~kb}$ NsiI/BamHI fragment from the vector pGN28 containing the Otx1 $5^{\prime}$ sequence was ligated into pBSK+ restricted with PstI/BamHI to produce the plasmid pBSKOtx1. Plasmid pSW2, containing the truncated murine Fgfr1 (IIIc) cDNA flanked by the $\beta$-globin intron and the human growth hormone polyadenylation region (Werner et al., 1993), was restricted with BamHI/SacII and linked with the following oligonucleotides: 5 '-GGGCGGCCGCGTCGACTCTAGACTCGAGTCGCGACACGTGG and 5'-CGCCCGCCGGCGCAGCTGAGATCTGAGCTCAGCGCTGTGCACCCTAG to form the derivative plasmid pSW2-oligo. The Otx1 $5.4 \mathrm{kB}$ promoter was then released from pBSKOtx1with SalI/BamHI and ligated into pSW2-oligo previously restricted with SalI/BamHI to make the final construct, named pSW2oligoOtx1. A $\sim 7.8 \mathrm{~kb}$ fragment containing the Otx $15^{\prime}$ region followed by the truncated murine Fgfrl, including the polyA sequence, was released from pSW2oligoOtx1 with KpnI/NotI and purified by sucrose gradient centrifugation before injection into the pronuclei of 1-cell embryos using methods described previously (Shashikant et al., 1995).

In situ hybridization. $\left[{ }^{35} \mathrm{~S}\right]$-labeled RNA probes were synthesized from cDNAs by in vitro transcription. The tFgfr $1 \mathrm{mRNA}$ was detected using a $600 \mathrm{bp}$ fragment encoding for the human growth hormone poly (A) region subcloned from pSW2 (Robinson et al., 1995). Paraformaldehyde-fixed (4\%) and paraffin-embedded embryos were sectioned at $10 \mu \mathrm{m}$, dewaxed and rehydrated, treated with proteinase $\mathrm{K}$ (5 $\mu \mathrm{g} / \mathrm{ml}$ ), and acetylated according to standard protocols (Wilkinson and Nieto, 1993). Sections were hybridized with $1 \times 10^{6} \mathrm{cpm} /$ slide of $\left[{ }^{35} \mathrm{~S}\right]$ labeled probe for $18 \mathrm{hr}$ at $60^{\circ} \mathrm{C}$. Slides were treated with RNase A $(10$ $\mu \mathrm{g} / \mathrm{ml}$ ) and washed to a final stringency of $0.1 \times$ SSC. Slides were coated with emulsion and developed.

Reverse transcriptase-PCR analysis. Embryos were collected in ice-cold
$1 \times$ PBS and were immediately subjected to tissue homogenization in TRIZOL reagent (15596; Invitrogen, San Diego, CA) for isolating RNA. Single strand of cDNA was synthesized by using the SuperScript FirstStrand Synthesis System for reverse transcriptase (RT)-PCR (Invitrogen) as directed in the instruction provided by the manufacturer. PCR was performed with $1 \mu \mathrm{g}$ of cDNA. The tFgfr1 expression was verified with primers in the Otxl promoter and the $\beta$-globin regions as illustrated with arrows in Figure 1 B. Glyceraldehyde-3-phosphate dehydrogenase primers were used to ensure the integrity as well as the quantity of the cDNA loaded in each RT-PCR.

Immunohistochemistry. Brain tissue was fixed in $4 \%$ paraformaldehyde overnight and cryosectioned at 14,20 , or $50 \mu \mathrm{m}$ after sucrose treatment. The tissue sections were blocked in $10 \%$ fetal bovine or goat serum for 1 $\mathrm{hr}$ at room temperature and processed as described previously (Korada et al., 2002). Fluorescent secondary antibodies were anti-mouse or antirabbit Alexa 488 and Alexa 596 (Molecular Probes, Eugene, OR). For immunoperoxidase color development, the Vector Laboratories ABC kit (PK-6100; Vector Laboratories, Burlingame, CA) was used as directed. The dilutions used for primary antibodies were as follows: rabbit-Tbr1 (1:1000; kind gift from Dr. R. Hevner, University of Washington, Seattle, WA), rabbit-GLAST (astrocyte-specific glutamate transporter; 1:2000; kind gift from Dr. M. Watanabe, Hokkaido University, Sapporo, Japan), rabbit-BLBP (brain lipid-binding protein; 1:1000; kind gift from Dr. N. Heintz, Rockefeller University, New York, NY), mouse-SMI-32 (1:1000; Sternberger Monoclonals, Lutherville, MD), mouse-RC-2 (1:400; Developmental Studies Hybridoma Bank, University of Iowa, Iowa City, IA), mouse-parvalbumin (clone PA-235; 1:1000; Sigma, St. Louis, MO), mouse-reelin (clone G10; 1:1000; Chemicon, Temecula, CA), rabbitPAX6 (AB5409; 1:1000; Chemicon), mouse-calretinin (MAB1568; 1:4000; Chemicon), rabbit-calbindin D-28K (AB1778; 1:5000; Chemicon), and mouse- $\beta$ III tubulin (clone 5G8; 1:3000; Promega, Madison, WI).

Bromodeoxyuridine incorporation assay. Dams harboring embryonic day (E) 12.5 embryos were injected with 5-bromodeoxyuridine (BrdU; $0.05 \mathrm{mg} / \mathrm{gr}$, i.p.) $30 \mathrm{~min}$ before harvesting embryos. The embryos were fixed in $4 \%$ paraformaldehyde, frozen at $-80^{\circ} \mathrm{C}$, and sectioned at $14 \mu \mathrm{m}$. To denature DNA, sections were incubated in $50 \%$ formamide $/ 50 \% 2 \times$ SSC buffer $\left(0.3 \mathrm{M} \mathrm{NaCl} / 0.03 \mathrm{M}\right.$ sodium citrate) for $2 \mathrm{hr}$ at $65^{\circ} \mathrm{C}$, rinsed in $2 \times \mathrm{SSC}$ for $5 \mathrm{~min}$, and incubated in $2 \mathrm{~N} \mathrm{HCl}$ for $30 \mathrm{~min}$ at $37^{\circ} \mathrm{C}$, followed by $0.1 \mathrm{~m}$ boric acid buffer, $\mathrm{pH} 8.5$. The sections were then processed for immunoperoxidase staining with a monoclonal anti-BrdU antibody (mouse clone B44; 1:300; Becton Dickinson, Rutherford, NJ).

Morphometric analyses and cell counts. Volumes and total cell number were assessed by unbiased stereological methods using the optical fractionator method (Raballo et al., 2000). For this purpose, series of sections (1:10 or 1:20) immunostained with BrdU, GABA, and TBR1 and counterstained with cresyl violet were analyzed using a computer-coupled microscope running StereoInvestigator (MicroBrightField, Colchester, VT). The boundaries for the E12.5 dorsal ventricular zone were drawn at $10 \times$ on the basis of published criteria (Takahashi et al., 1993; Raballo et al., 2000), and those for the adult cerebral cortex (neocortex) were drawn on the basis of described boundaries (Franklin and Paxinos, 1997). A volume estimate was obtained by the Cavalieri method using the area estimates, section thickness, and the spacing of sections. Stained cells were counted within sampling boxes $(50 \times 50 \times 6 \mu \mathrm{m})$ chosen in a systematically random manner within the areas of interest. The coefficient of error of our estimates was $<0.2$. To estimate the number and density of BrdU-labeled cells in the lateral portion of the VZ, BrdUpositive nuclei were counted by using the optical fractionator method along the anteroposterior domain of the dorsal VZ in a $100 \mu \mathrm{m}$ wide strip situated immediately dorsal from the corticostriatal sulcus.

Analysis of apoptosis. Apoptosis was detected in embryonic tissue sections by terminal transferase-mediated dUTP nick end labeling (TUNEL) as described previously (Raballo et al., 2000).

Behavioral studies and analyses. Mice were housed in groups in plastic cages with corn chip bedding with food and water available ad libitum. Both male and female transgenic and littermate controls were used. The animal colony was climate controlled and kept on a $12 \mathrm{hr}$ light/dark cycle. Data are expressed as mean activity counts, \pm SEM, measured by photo- 


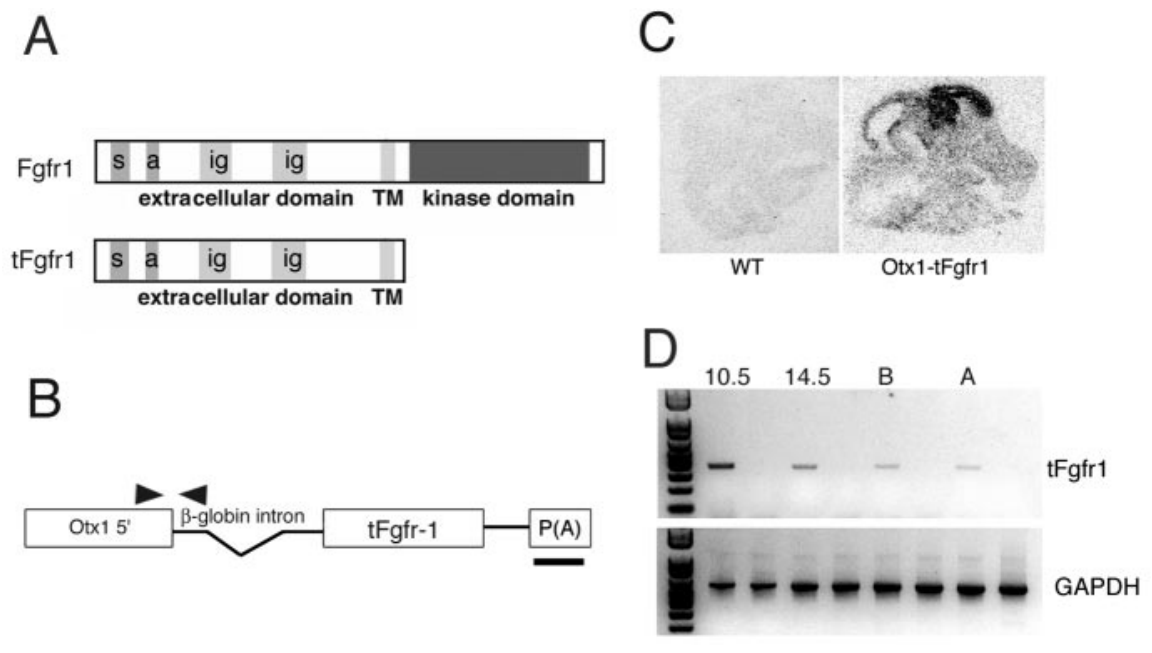

Figure 1. Structure and expression of the 0tx1-tFgfr1 transgene. $A$, Structure of the mouse two-Ig variant Fgfr 1 gene product and the kinase domain-truncated $t F g f r 1$ construct. S, Signal sequence; $a$, acidic box; ig, immunoglobulin-like domain; TM, transmembrane domain. $B$, The tFgfr 1 construct was placed downstream from the $0 t \times 15^{\prime}$ region and $\beta$-globin intron and upstream from the human growth hormone polyadenylation region $P(A)$. Transgene-specific sequences used as probes for in situ hybridization are indicated by a black bar, and sequences used to design PCR primers are indicated by arrowheads. C, In situ hybridization with the transgene-specific probe indicated in $B$, showing that line 33 mice express the 0tx1-tFgfr1 gene in the telencephalon, diencephalon, and mesencephalon when examined at E14.5. D, Time course RT-PCR for the transgene mRNA expression level in brain at different developmental time points (10.5, E10.5; 14.5, E14.5; B, birth; A, adult at 6 months of age).
The mice demonstrated intense LacZ staining restricted to the dorsal telencephalon, mesencephalon, and the dorsal region of the eye at E9.5 and E11.5 (data not shown). We then produced five transient transgenic founders, which carried the Otx1-tFgfr1 construct; three of these founders were harvested at E14.5 and two at E18.5 (Table 1) (supplemental Fig. $1 A$; available at www. jneurosci.org). After cresyl violet staining of serial sections, gross morphological abnormalities were evident in the two E18.5 Otx1-tFgfr1 transgene-positive embryos. These included a thinner cortical plate, an enlargement of the cerebral ventricles, and a shortening of the mesencephalon(supplemental Fig. 1C; available at www. jneurosci.org). The transgene was strongly expressed throughout the Otxl domain, including the developing cerebral cortex, as detected by in situ hybridization using a transgene-specific probe (supplemental Fig. $1 B$; available at www.jneurosci.org). Additional zygote microinjections resulted in four Otx1-tFgfr1transgene-positivefounders, numbers 2, 16, 19, and 33 (Table 1). Founder lines 16, 19, and 33 discell total beam brakes. Animal protocols were approved by the Yale University Animal Care and Use Committee and following the Guide for the Care and Use of Laboratory Animals. Locomotor activity was quantitated using the automated Accuscan (Columbus Instruments, Columbus, OH) Digiscan Micro-monitor system equipped with 16 photocells per chamber. Locomotor activity was collected in 5 min intervals. The activity chambers were located inside a soundattenuated room equipped with a white noise generator. During activity testing, the room was illuminated with red light only. Animals were habituated to the apparatus for $30 \mathrm{~min}$ before injections were given. Immediately after intraperitoneal injection of amphetamine (D-amphetamine sulfate given at $2.0 \mathrm{mg} / \mathrm{kg}$ ) or guanfacine $(1.0 \mathrm{mg} /$ $\mathrm{kg}$ ), the mice were returned to the apparatus for an additional $60 \mathrm{~min}$. The dose for guanfacine was selected on the basis of a study in which this dose was found to enhance the performance of mice on a prefrontal cortex task without sedation (Franowicz et al., 2002). Drugs were dissolved in sterile saline. Locomotor activity was analyzed by ANOVA with repeated measures (time) for the experimental groups. Significant behavioral effects were further analyzed by factorial ANOVA with Scheffe's F test for post hoc analyses.

\section{Results}

\section{A truncated form of Fgfr 1 is expressed in the developing prosencephalon}

To investigate the role of FGFR signaling during forebrain development, we used a truncated Fgfrl gene construct that has been shown to successfully antagonize FGFR signaling when expressed in vivo (Werner et al., 1993; Robinson et al., 1995). This truncated Fgfr1 (tFgfr1) contains the transmembrane domain but lacks the tyrosine kinase region. Therefore, it inserts into the cell membrane, binds ligands, and crossdimerizes with endogenous FGFR, blocking their function (Ueno et al., 1992) (Fig. 1A). The tFgfr1 construct was placed downstream of a $5.4 \mathrm{~kb}$ region encompassing the Otx 1 promoter-enhancer (Fig. $1 B$ ). We previously characterized the Otx1 $5.4 \mathrm{~kb} 5^{\prime}$ region by placing it upstream from a $\beta$-galactosidase reporter gene and expressing the construct in transgenic mice. played spontaneous hyperactive locomotor behavior in the home cage. Lines 16 and 19 were incapable of producing any progeny beyond $\mathrm{F}_{1}$ because of unidentified reasons but possibly because of extreme hyperactivity. Line 2 mutant animals were indistinguishable from wild types in terms of body weight, brain weight, and general brain morphology. In contrast, line 33 mutant animals were immediately identifiable by their hyperactivity and smaller body size. The brain weight for line 33 mutant mice was consistently decreased by $16 \%$ compared with their wild-type littermates at birth as well as at adulthood $[0.125 \pm 0.03$ vs $0.104 \pm$ $0.08 \mathrm{gm}$ at postnatal day (P) $1 ; n=13$ per group]. All four lines expressed the tFgfrl mRNA in the forebrain and midbrain throughout embryogenesis but at different levels. For example, lines 19 and 33 had much stronger tFgfr1 expression in the cortical primordium than line 2 (Fig. $1 C$ ) (data not shown). This suggests that phenotypic differences between these lines were attributable to different expression levels of the transgene.

The spatiotemporal pattern of transgene expression was regulated during development. In line 33, tFgfr 1 mRNA was highly expressed in the forebrain and to a lower extent in the midbrain at E12.5-E14.5 and was downregulated at birth (Fig. 1C) (data not shown). To confirm these data, we collected brain tissue from forebrain and midbrain areas and subjected them to RT-PCR at four different time points: E10.5, E14.5, $\mathrm{P} 0$, and 6 months. Together with the in situ hybridization results, the RT-PCR data (Fig. 1D) indicated that the transgene is downregulated at the mRNA level by the end of gestation and that a lower level of transgene expression is retained until adulthood. This time-dependent expression pattern of the transgene correlates with the expression time frame of Otx1, which begins at E8.5 with a steady increase until E12.5 and subsequently is downregulated in most regions (Simeone et al., 1993). No decrease in Otx1 mRNA levels was present in tFgfr 1 transgenic mice (data not shown). 
Table 1. Summary of all transgenic founders or lines that were produced and analyzed

\begin{tabular}{llll}
\hline & & Fertility and survival & Cortical phenotype \\
\hline $4,6,8$ & Harvested at E14.5 & N/A & N/A \\
21,22 & Harvested at E18.5 & N/A $/ A$ & Present \\
2 & Line & Fertile & Absent \\
16 & Line & No progeny beyond F & Present \\
19 & Line & No progeny beyond F 1 & Not analyzed \\
33 & Line & Fertile & Hyperactivity \\
\hline
\end{tabular}

Dysfunctional FGFR signaling severely alters the differentiation of the cerebral cortex in a region-specific manner

Otx1-tFgfr1 transgenic mice showed an aberrant development of specific regions of the CP. When embryos were examined at E18.5, when the marginal zone (MZ), $\mathrm{CP}$, subplate (SP), intermediate zone (IZ), and $\mathrm{VZ}$ were all distinctly formed, the $\mathrm{CP}$ and IZ of all transgenic mice examined with the exception of line 2 were notably thinner with respect to wild-type mice. Mice from lines 33 and 19 were examined in greater detail throughout subsequent development. In serial coronal sections examined at $\mathrm{P} 0$ or $\mathrm{P} 2$, the $\mathrm{CP}$ was reduced in thickness in the prospective medial prefrontal and temporal cortical areas, whereas other cortical areas were indistinguishable from that of wild-type littermates (Figs. 2A-H). At higher magnification, cortical neurons appeared less dense and disorganized in the prospective medial prefrontal and temporal cortical regions of neonatal transgenic mice (Fig. 2 I$L)$. This abnormality was noticed in all tFgfr 1 mutant brains analyzed $(n=10)$.

The severity of the cerebral cortical abnormalities progressed with age. For example, the adult frontal and temporal cortical areas were reduced in thickness by $\sim 30-40 \%$, primarily because of a near collapse of infragranular cortical layers (Fig. 3, compare $F$ with $G$ and $H$; Fig. 4, compare $A$ and $I$ ). The amount of subcortical white matter was similarly reduced (Fig. $3 A-D$ ). At higher magnification in cresyl violet-stained sections, a reduction in the number of cortical cells and a decrease in soma size as well as aberrant cortical layer architecture were immediately apparent in the tFgfr 1 mutants. In the dorsolateral frontal regions, layer 5 large-sized neurons were very sparse, and layers 5 and 6 were indistinct from one another (Fig. 3, compare $K$ with $L$ and $M$ ). In the temporal regions of the pallium, above the rhinal sulcus, the cortex was reduced to a narrow strip of tissue with indistinguishable cortical layers (Fig. 4, compare $B$ and $J$ ). No apparent abnormalities were present in other regions of the cerebral cortex.

To investigate the cellular composition of the cerebral cortex, we analyzed adult brains for two major cortical neuron subtypes: glutamatergic projection neurons and GABAergic interneurons. SMI-32 recognizes a nonphosphorylated epitope of neurofilament $\mathrm{H}$ in cortical pyramidal cells (Campbell et al., 1991). Most notable alterations in SMI-32 staining pattern were found in frontal and temporal cortices. In mutant frontal cortex, both in medial and dorsal regions, fewer neuronal cell bodies were found to be immunoreactive with
SMI-32, and these pyramidal neurons were smaller in size and less compactly organized in distinct layers (Fig. 3, compare $N$ with $O$ and $P$ ). Apical dendritic processes of pyramidal cells were short, and their bundles were substantially thinner in diameter (Fig. 3, compare $A$ and $B$ with $C-E$, and $N$ with $O$ and $P)$. More severe alterations in SMI-32 staining were found in the adult temporal cortical area. In this region, the mutant cortex contained very few pyramidal cells, the cell bodies of which were much smaller and scattered randomly without any discernible aggregation into layers II/III and $\mathrm{V}$ and without distinguishable apical dendritic processes (Fig. 4, compare $F$ and $N$ ).

The abnormalities in cortical pyramidal cells were present in animals from both lines 33 (Fig. 3C,D,O) and 19 (Fig. 3E,P), which both exhibited marked spontaneous locomotor hyperactivity as compared with wild-type littermates. To obtain an estimate for the decrease in number of pyramidal neurons in infragranular layers of the cerebral cortex, we immunostained sections for TBR1, a transcription factor expressed by glutamatergic neurons of the cerebral cortex in layer 5/6 (Hevner et al., 2001). Stereological analyses revealed a pronounced decrease in TBR1-immunoreactive neuron number in tFgrl transgenic mice as compared with wild-type littermates (Table 2). Pyramidal neurons represent approximately two- 

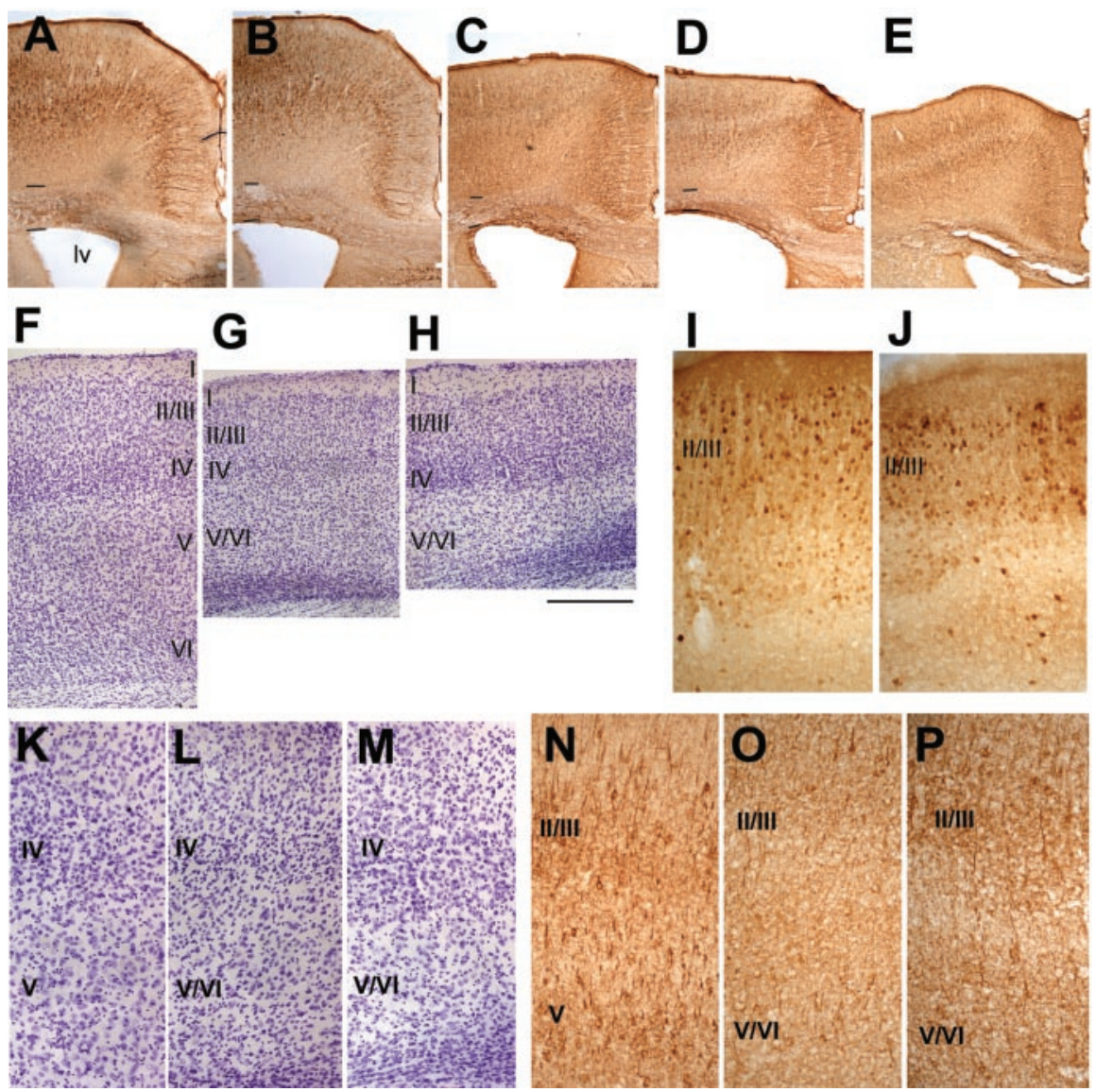

Figure 3. Cytoarchitecture and cellular phenotypes in the adult prefrontal cortex. $A, B, F, I, K, N$, Wild type; $C, D, G, H, J, L, M, O$, tFgfr 1 line $33 ; E, P$, tFgfr 1 line 19. $A-E$, Fewer $S M I-32$ immunoreactive pyramidal projection neurons with less prominent apical dendrites are present in two tFgfr1 mice from line $33(C, D)$ and line $19(E)$ as compared with two littermate controls $(A, B)$. Black bars in $A-D$ delineate subcortical white matter. $F-H$, Cresyl violet staining shows greatly decreased thickness of infragranular cortical layers in the dorsal prefrontal cortex of the two 0 tx 1 -tFgfr1 mutants of line $33(G, H)$ as compared with the wild-type control $(F) . I, J$, Calbindin-immunoreactive interneurons in top layers are not substantially affected in tFgfr 1 transgenic mice. $K-P$, High magnification of the cresyl violet staining and SMI-32 immunostaining in dorsal prefrontal cortex demonstrating the collapsed cortical laminas and apparent absence of large pyramidal neurons of layer 5 in line 33 tFgfr1 mutant mice $(L, M)$ as compared with the wild-type control ( $K$. Also note the decreased density of SMI-32-positive pyramidal neurons and decreased immunostaining of apical dendrites in line 33 and line 19 mutants $(O, P)$ as compared with the wild-type mouse $(N)$. Right is medial and top is dorsal in all figures; cortical layers are in roman numerals. Scale bars: $A-E, 400 \mu \mathrm{m} ; F-H, 200$ $\mu \mathrm{m} ; I-P, 100 \mu \mathrm{m}$.

thirds of all cortical neurons; correspondingly, cortical volume as well as the total number of cells was significantly decreased in Otx1-tFgfr1 mutant mice (Table 2).

We next examined GABAergic interneurons. The expression pattern or the density of neurons immunostained by GABA antibodies was not altered in frontal, temporal, or any other cortical areas examined, and the total number of GABAimmunoreactive cortical neurons was not significantly changed in transgenic mice (Table 2). The calcium-binding protein, calbindin-28KD, is expressed by GABAergic interneurons in layers II through VI as well as by layer 2 pyramidal cells (Cruikshank et al., 2001). The expression pattern of calbindin-immunoreactive neurons was not affected in frontal cortex (Fig. 3I,J), whereas calbindin-immunoreactive neurons were decreased in the mutant temporal cortex (Fig. 4, compare $E$ and $H$ with $M$ and $P$ ). Another calcium-binding protein, parvalbumin, is expressed by a different subset of GABAergic interneurons distributed uniformly throughout the cortical layers. In mutants, the density of parvalbumin neurons was unchanged or slightly increased in both frontal and temporal areas (Fig. 4, compare $D$ and $G$ with $L$ and $O$ ).

Because of the locomotor hyperactivity of these animals (see below) we also examined subcortical structures and cor- tical afferent fiber systems that are known to affect psychomotor behavior. At the stages of young adults, as well as at complete maturity, transgenic mice of lines 33 and 19 showed no difference in volume, cellular composition, or innervation of the basal ganglia, as demonstrated by GABA, parvalbumun, calbindin, serotonin, and dopamine transporter (DAT) immunostaining (data not shown). The normal immunostaining results in the basal ganglia are in agreement with the lack of transgene expression in the basal telencephalon (Fig. 1C). In addition, the density or pattern of the few cortical terminals expressing DAT and serotonin immunoreactivities was not different as compared with controls.

In conclusion, the cresyl violet staining, SMI-32, TBR1, and calbindin immunostaining results provided consistent evidence for region-specific neocortical atrophy and disorganization of cerebral cortical laminar structure in transgenic mice. This included a defect in the number and positioning of pyramidal neurons in frontal and temporal areas as well as altered morphology of their dendritic trees. In contrast, the number of cortical GABAergic interneurons was unchanged, and several subcortical systems examined were likewise unaffected. 

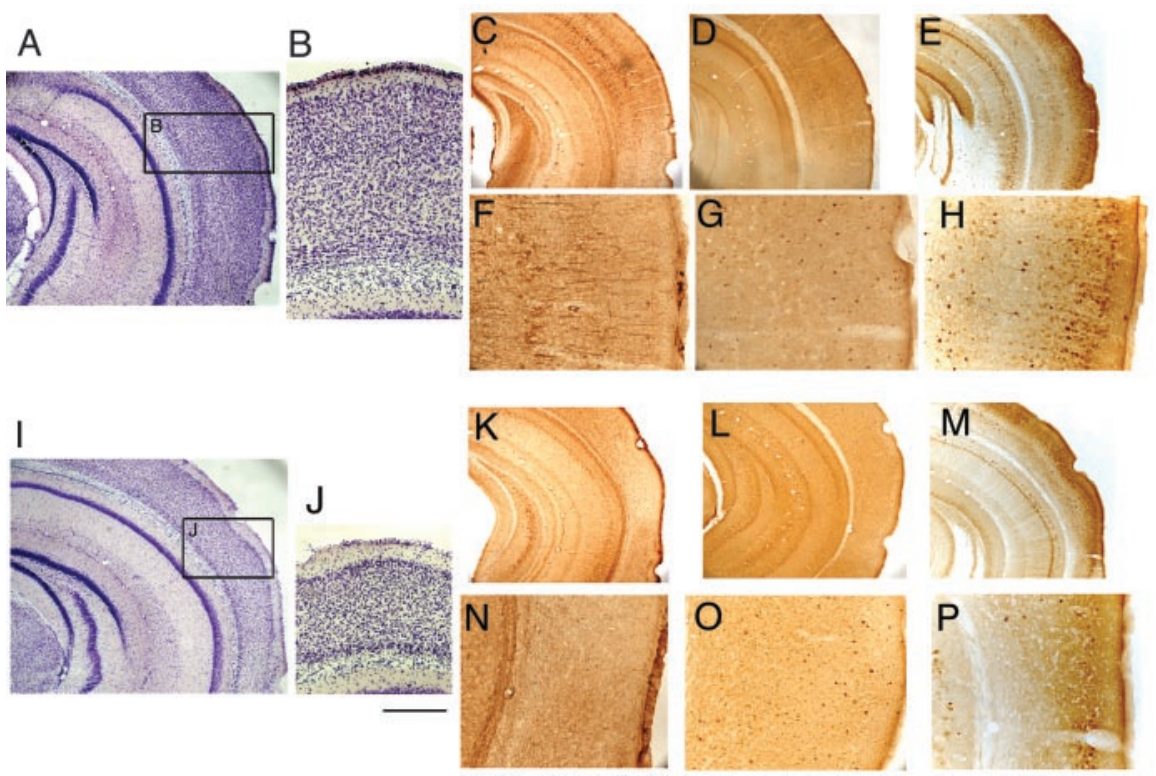

Figure 4. Cytoarchitecture and cellular phenotypes of the temporal cortex at adulthood. $A-H$, Wild type; $I-P, t F g f r 1$. Cresyl violet staining of adult coronal sections showing the temporal cortical region of wild type $(A)$ and $\operatorname{tFgfr} 1(I) . B$ and $J$ are enlarged views of the boxed areas in $A$ and $I$, respectively. Note the absent layer organization of the temporal cortical area in $J$. SMI-32 immunoperoxidase staining of wild type $(C, F)$ in the temporal cortical area. $F$ is a high magnification of $C$. Note the absence of SMI-32 immunoreactive cell bodies or the apical dendrites in the corresponding cortical area in transgenic animals $(K, N)$. N is the enlarged view of $K$. In contrast, the density of GABAergic cells seems unaffected in transgenic animals $(L, 0)$ compared with the wild-type counterparts $(D, G)$. $G$ and $O$ are the enlarged views of $D$ and $L$, respectively. There is decreased density of calbindin-28KD-immunoreactive cells in deeper layers of the temporal cortical area in transgenic animals $(M, P)$ as compared with wild-type mice $(E, H)$. $H$ and $P$ are enlarged views of $E$ and $M$, respectively. Scale bars: $A, C-E, I, K-M, 400 \mu \mathrm{m} ; B, F-H, J, N-P, 100 \mu \mathrm{m}$.

Table 2. tFgfr1 transgenic mice show a significant decrease in pyramidal neurons, whereas GABA interneurons are not significantly changed

\begin{tabular}{|c|c|c|c|c|}
\hline & \multicolumn{3}{|c|}{ Total cell number (millions) \pm SEM } & \multirow[b]{2}{*}{ Volume $\left(\mathrm{mm}^{3}\right)$} \\
\hline & TBR1 & GABA & Total cells & \\
\hline Wild type & $7.0 \pm 1.2$ & $5.9 \pm 1.3$ & $20.5 \pm 1.2$ & 86.2 \\
\hline tFgfr1 & $3.8 \pm 0.92^{*}$ & $4.3 \pm 0.74$ & $12.75 \pm 1.2^{*}$ & $53.2^{*}$ \\
\hline Percentage of decrease & 45.7 & 27.1 & 37.8 & 38.3 \\
\hline
\end{tabular}

Infragranular pyramidal neurons and GABA interneurons were identified by immunostaining for the transcription factor TBR1 and GABA, respectively. Sections were counterstained with cresyl violet to visualize all cells. Cell number in the adult neocortex was estimated by stereological analysis using the optical fractionator method. ${ }^{*} p<0.01 ;$ Student's $t$ test; $n=4-6$ mice per genotype.

\section{Region-specific disruption of radial glia in tFgfr 1 cerebral cortex}

Radial glial cells are progenitors that generate cortical pyramidal neurons as well as guide their migration (Anton et al., 1997; Malatesta et al., 2000, 2003; Noctor et al., 2001). To test the hypothesis that the disturbed number and laminar organization of cortical pyramidal neurons may be attributed to defective radial glia, we examined radial glial phenotypes in wild-type and tFgfr1 transgenic mice using molecular markers. The RC-2 monoclonal antibody recognizes an epitope present in radial glia but not in mature astrocytes (Misson et al., 1988). At E18.5, RC-2immunoreactive radial glia apical processes were decreased in number in the prospective medial prefrontal and temporal cortical areas of tFgfr 1 mutants, whereas RC-2-immunoreacitve radial glia fibers were elongated and extended from the VZ to the pial layer in wild-type littermates (Fig. $5 A, D$ ) (data not shown). A different type of radial glia marker, GLAST, is expressed by a subtype of radial glia partially overlapping with the subset of radial glia recognized by RC-2 (Shibata et al., 1997; Hartfuss et al., 2001). GLAST immunofluorescent staining at E18.5 was in accord with the results obtained with the RC-2 monoclonal antibody. Astroglial fibers were disorganized, fragmented, and discontinuous in the mutant $\mathrm{CP}$ within prospective frontal and temporal cortical regions (Fig. $5 E, F$ ), whereas they extended from the VZ to the cortical wall without any interruption in wild-type littermates (Fig. $5 B, C$ ). Immunostaining with a third radial glial marker, BLBP (Feng et al., 1994; Rousselot et al., 1997), confirmed the lower densities of radial glial fibers in the cortical wall (data not shown). In summary, there was abnormal radial glia process extension in $\mathrm{tFgfr} 1$ mutant mice, as revealed by RC-2, GLAST, and BLBP in the prospective medial prefrontal and temporal areas of the neocortex. There was no evidence that these abnormalities were attributable to premature radial glia differentiation into astrocytes, because no GFAP immunoreactivity was detected in the mutant $\mathrm{CP}$, and none of the above markers revealed upward displacement of radial glial cell bodies toward the CP.

\section{Disrupted FGFR signaling causes region-specific decreases in} proliferative cells and early generated neurons

The radial glial cells arise at E13.5 from primordial neuroepithelial cells of the VZ (Malatesta et al., 2003). These primordial neuroepithelial cells give rise, in addition to radial glia, to some of the neurons that form the preplate or primordial plexiform layer (PPL), which will be subsequently split by the incoming neurons of the CP into layer I and SP (Luskin and Shatz, 1985; MarinPadilla, 1998). To find out whether the alterations in radial glial cells noted at E18.5 were preceded by previous alterations in VZ neural progenitor cells, we examined the animals at E12.5, a time 

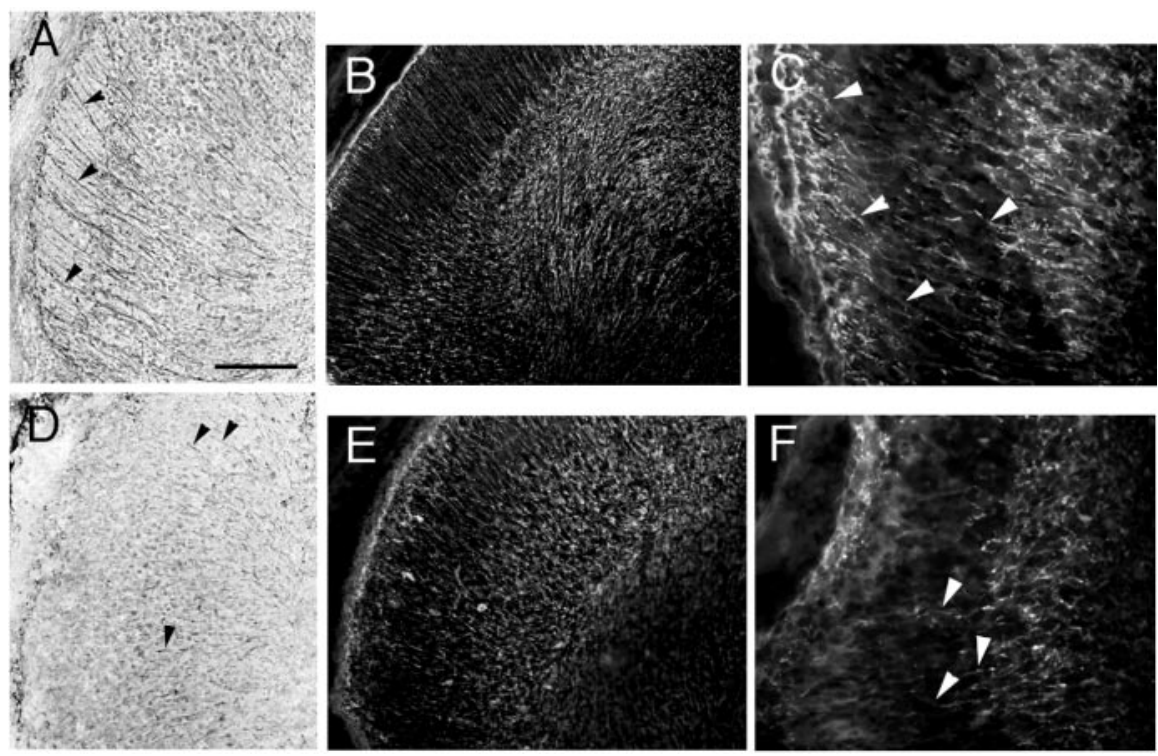

Figure 5. Radial glia morphology in the developing cerebral cortex at E18.5. $A-C$, Wild-type mice; $D-F$, tFgfr1 mutants. $A, D$, RC-2 immunoperoxidase staining of the medial prefrontal areas taken from midsagittal brain sections of E18.5 embryos. Note the elongated radial glial fibers reaching the pial layer in wild type ( $A$, arrowheads) and the fewer, fragmented, abnormal glia fibers in tFgfr $1(D$, arrowheads). Anterior is to the left. $B-F, G L A S T$ immunofluorescence staining of the temporal cortical areas taken from coronal brain sections at the level of lateral geniculate nuclei $(B, E)$ or at more posterior levels $(C, F)$. Note similar absence of elongated radial glial processes in $\mathrm{tFgfr} 1(E, F)$ as compared with wild type $(B, C)$. Arrowheads point to radial glial processes in the CP. Medial is to the right and dorsal is to the top. Scale bars: $A, C, 100 \mu \mathrm{m} ; B, D, 200 \mu \mathrm{m} ; C, F, 50 \mu \mathrm{m}$.

point when the genesis of the CP has not yet begun and before the preplate has split into the marginal zone and the SP.

We detected a region-specific reduction in thickness of both the PPL and the VZ in the cortical wall of E12.5 tFgfr1 embryos. The lateral cortical neuroepithelium was severely atrophic in the mutants, and this reduction in thickness of the VZ was accompanied by a reduction in number of proliferative cells labeled by BrdU administered to the embryos 30 min before harvest (Fig. $6 A-D)$. The number of BrdU-positive cells in a longitudinal strip of dorsal $\mathrm{VZ}$ adjacent to the lateral ganglionic eminence, measuring $100 \mu \mathrm{m}$ in the lateral-medial dimension, was $68,484 \pm 4158$ in wild type and 34,268 \pm 1643 in transgenic animals $(p<0.01$; Student's $t$ test). The volume of this strip of neuroepithelium was not statistically different between wild-type and transgenic animals $(0.12 \pm 0.03$ and $0.08 \pm 0.01$, respectively; $n=3$ wild type and 3 transgenic embryos). The total number of BrdU-labeled proliferative cells in the entire cortical VZ of tFgfr 1 embryos did not differ from that of wild type (data not shown), suggesting that the abnormal proliferation was highly localized in the lateral cortical neuroepithelium. Cell death, as assessed by TUNEL staining, was not affected in tFgfr1 embryos (Fig. 6E,F).

Postmitotic neurons were visualized with antibodies to $\beta$-III tubulin and TBR1, a transcription factor expressed by early born neurons of the PPL (Hevner et al., 2001) (Fig. 6G,H). A reduction in thickness of the PPL and decreased TBR1 expression was observed in the anteromedial and lateral regions of the cerebral cortical wall (Fig. 6G,H) (data not shown). In contrast, in posterior regions of the cortical epithelium of E12.5 tFgfr1 embryos, the thickness of the VZ and the neuronal density in the PPL were comparable with that of wild-type littermates (data not shown). Some of the neurons of the PPL are Cajal-Retzius cells, which express reelin and calretinin (Lavdas et al., 1999). However, when examined at either E12.5 or E18.5, tFgfr1 mutants showed no significant difference in the expression level of either reelin or calretinin immunoreactivities (data not shown).
We next examined whether altered expression pattern of TBR1 was present at subsequent developmental stages. At E18.5, TBR1 is expressed by neurons of the $\mathrm{MZ}$ and SP as well as by glutamatergic neurons of the CP; TBR1 expression is maintained in layer 5/6 pyramidal neurons through adulthood (Hevner et al., 2001). Mutant animals showed aberrant TBR1 protein expression only in presumptive medial prefrontal and temporal cortical areas, whereas other cortical areas displayed TBR1 expression comparable with that of wild-type embryos (Fig. 7A-L). In the affected areas, there was a substantial reduction in TBR1 nuclear immunoreactivity in the marginal zone and deeper layers of the cortical plate. Most of TBR1 immunostaining in tFgfrlmutants was cytoplasmic, in contrast to the discrete nuclear staining pattern observed in wildtype littermates (Fig. 7, compare $B, C$, and $E$ with $G, H$, and $L$ ). The reduction in TBR1-positive neuron number persisted in adulthood (Table 2).

Transgenic animals have hyperactivity, which is increased by amphetamine and alleviated by guanfacine treatment

The tFgfr 1 mutant animals developed behavioral abnormalities characterized by repetitive patterns of locomotor hyperactivity that were stereotyped in nature. The abnormal behavior was evident at baseline, in the home cage. Each animal repetitively and compulsively turned in one particular direction and also displayed occasional head bobbing. Interestingly, this stereotyped behavior was not present at birth but developed $\sim 2$ weeks after weaning, during adolescence, or young adulthood. It persisted in adulthood, although the frequency of locomotor hyperactivity declined slightly with age.

Baseline activity levels assessed after a saline injection were markedly increased in tFgfr 1 mice compared with control animals using an automated activity monitoring system (Fig. 8A) $\left(F_{(1,28)}=9.65 ; p<0.01\right)$, consistent with observations of spontaneous hyperactivity made in the animals' home cages. To evaluate whether the locomotor hyperactivity could be attributable to a functional alteration of monoaminergic systems, we first tested whether the transgenic animals responded as the wild type to the stimulating effects of amphetamine. There were differences in activity rates between tFgfr1 compared with control mice after the injection of amphetamine $\left(F_{(1,16)}=6.53 ; p<0.05\right)$ (Fig. $\left.8 A\right)$. Nevertheless, amphetamine significantly increased activity rates by approximately twofold in both wild-type and transgenic animals $\left(F_{(11,18)}=4.43\right.$ and $F_{(11,26)}=2.32$, respectively; $\left.p<0.01\right)$ despite the different baselines. For both groups, activity was increased 5-10 min after the injection of amphetamine, but the effect differed over time $\left(F_{(11,44)}=3.28 ; p<0.01\right)$. Elevated activity rates in controls did not decline over the session, although they did in the transgenic animals. Thus, transgenic animals consistently displayed elevated activity rates compared with controls regardless of saline or amphetamine treatment $\left(F_{(1,44)}=\right.$ 16.28; $p<0.001$ ).

The systemic administration of $\alpha 2 \mathrm{~A}$ adrenergic receptor agonists inhibits impulsive behavior in both mice (Franowicz et al., 


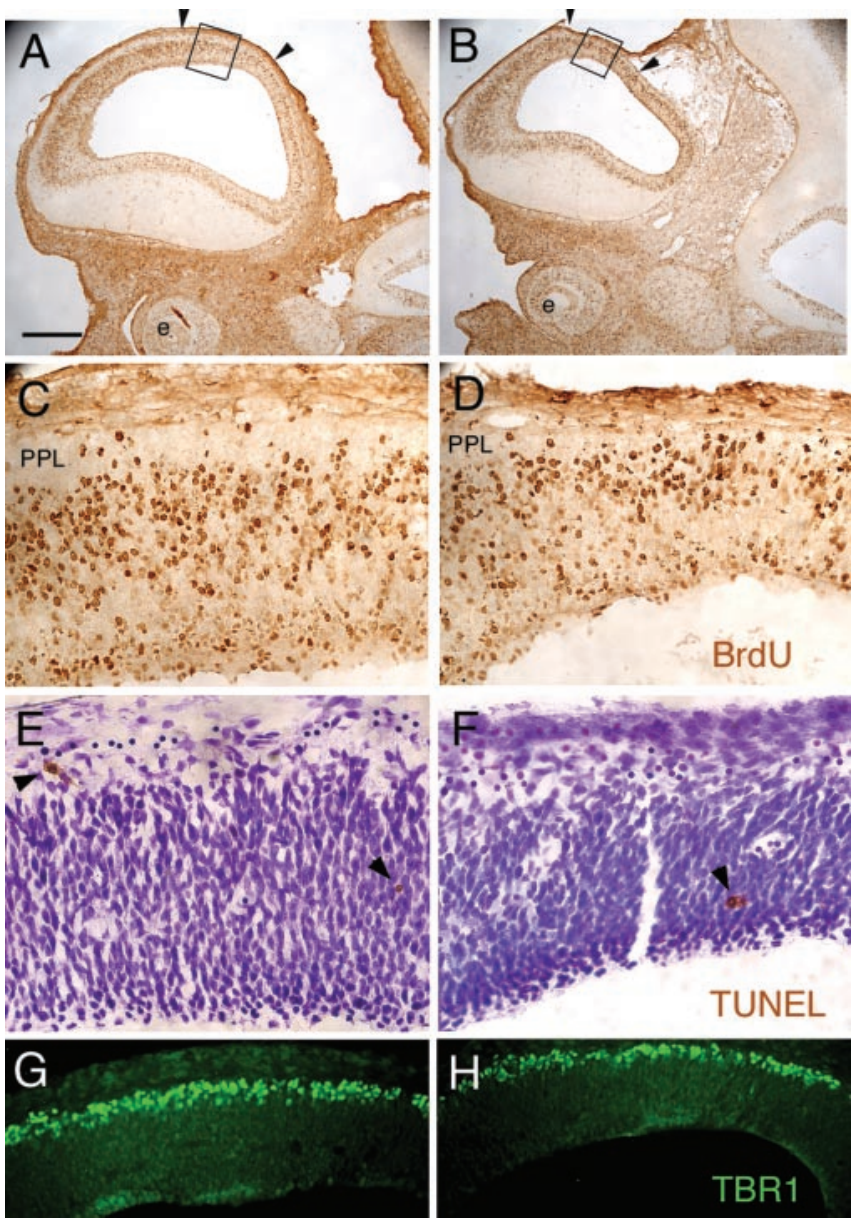

Figure 6. Decrease in cell proliferation but no changes in apoptosis in the presumptive temporal neuroepithelium and reduction in the number of TBR1 immunoreactive cells at E12.5. $A, C, E, G$, Wild type; $B, D, F, H$, tFgfr1. A-D, BrdU staining of lateral sagittal sections of $E 12.5$ embryos that were harvested 30 min after a BrdU injection. In tFgfr1 $(B, D)$, the number of BrdU-labeled cells as well as the thickness of the cortical neuroepithelium and the PPL are severely reduced in the middle portion of the prospective temporal cortex (indicated by arrows). ( and $D$ are enlarged views of the boxed areas in $A$ and $B$, respectively. $E, F$, No differences in apoptotic cells between wild type and tFgfr1 were noted by TUNEL staining. $E$ and $F$ are the adjacent sections of $A$ and $B$, respectively; arrowheads indicate TUNEL-positive cells (brown). Sections were counterstained by cresyl violet. $G, H$, The number of TBR1-immunoreactive cells is slightly reduced in the middle portion of the prospective temporal cortex where the defects were noticed with the BrdU labeling experiment. Scale bars: $A, B, 400 \mu \mathrm{m} ; C-F, 50 \mu \mathrm{m} ; G, H$, $100 \mu \mathrm{m}$.

2002) and children with attention-deficit hyperactivity disorder (Scahill et al., 2001). To further test whether behavioral hyperactivity observed in transgenic animals could be attributed to an abnormality of this receptor system, we assessed spontaneous locomotor activity before and after treatment with guanfacine, a drug preferentially acting at $\alpha 2 \mathrm{~A}$ adrenergic receptors. The systemic administration of guanfacine $(1 \mathrm{mg} / \mathrm{kg})$ markedly reduced locomotor activity in both wild-type and transgenic mice, although its effects differed for these groups in magnitude $\left(F_{(11,40)}\right.$ $=2.00 ; p<0.05)$ and in the time course of the drug action $\left(F_{(11,40)}=3.14 ; p<0.01\right)$ (Fig. $8 B$ ). Both groups of mice showed reductions in activity $5-10 \mathrm{~min}$ after the injection, yet the effects of guanfacine were transient in the $\operatorname{tFgfr} 1$ mice $\left(F_{(11,16)}=2.86\right.$; $p<0.05)$ and persistent in wild-type controls $\left(F_{(11,16)}=3.46 ; p<\right.$ $0.05)$. This may have been because of some sedative effects of this dose of guanfacine in control mice; however, no evidence of sedation or abnormal behavior was observed in transgenic animals.
Indeed, guanfacine appeared to restore normal rates and patterns of activity for $\sim 30 \mathrm{~min}$ in these tFgfr 1 mice, such that they were essentially identical to saline-injected controls (Fig. 8 B). Nevertheless, stereotyped patterns of locomotor hyperactivity gradually increased over time, such that eventually these mice were similar to tFgfr 1 mice that were given saline. These data indicate that guanfacine could transiently ameliorate the consequences of tFgfr 1 transgene-induced alterations during embryonic brain development on subsequent cortical function.

\section{Discussion}

We generated mice expressing a dominant negative tFgfr 1 transgene in the neuroepithelium of the embryonic brain and the developing cortical plate, which disrupts FGF receptor signaling by forming inactive complexes with endogenous FGFR. The Otx1tFgfr 1 mutants have decreased cortical thickness and decreased numbers of cortical pyramidal neurons in the prefrontal and temporal areas of the neocortex. Cortical architecture was disorganized at birth in these areas and progressively worsened during development, resulting in severe atrophy of the frontal and temporal regions in adulthood. In these regions, residual pyramidal cells were smaller and poorly organized in cortical layers, showing underdeveloped dendritic arborization. No significant alterations were observed in other areas of the cerebral cortex. The same transgenic mice exhibited marked increases in spontaneous stereotypic locomotor activity, which could not be attributed to a dysfunction of subcortical monoaminergic systems. Hence, our data provide the first in vivo evidence for a role of FGFRmediated tyrosine kinase signaling in cortical development and the regulation of locomotor behavior.

We believe that both the anatomical and behavioral defects arise as a result of the dominant negative attenuation of FGFR signaling resulting from transgene expression and not by an interference with other genetic loci. For example, a decreased thickness of the cortical plate was observed in the two transgenic founders harvested at E18.5, as well as in two of the lines, 19 and 33 , each one arising as an independent genetic integration event. Lines 19 and 33 also had locomotor hyperactivity, although we could only analyze line 33 in detail because of the inability of line 19 to give progeny beyond $F_{1}$. In contrast, line 2 did not show either hyperactivity or significant alterations in cortical morphology. This is likely because of the fact that the level of transgene expression was insufficient to antagonize endogenous FGF activity in line 2. Therefore, there is a good correlation between the level of tFgfr1 expression, aberrant cortical development, and locomotor abnormalities.

FGFRs, to our knowledge, are the earliest tyrosine kinase receptors to be expressed in the forebrain. The Fgfr1 and Fgfr2 gene products are expressed by neuroepithelial precursor cells of the cerebral cortex (Raballo et al., 2000; Y. Ohkubo and F. Vaccarino, unpublished data). The overexpression of tFgfr1 via the Otx1 promoter was sufficient to interfere with the proliferation of neural progenitor cells resulting in atrophy of anteromedial and lateral regions of the neuroepithelium at E12.5. Precisely in these regions, the decreased number of neural progenitor cells resulted in decreased production of neurons expressing the transcription factor TBR1 in layer 5/6 pyramidal neurons. Tbr 1 is required for normal reelin expression in Cajal-Retzius cells within the PPL (Hevner et al., 2001), which in turn is necessary for pyramidal cell migration to the CP (Caviness, 1982; D'Arcangelo et al., 1995). In Tbr1 null mutants, cortical layers are disorganized because of a downregulation of reelin within Cajal-Retzius cells (Hevner et al., 2001). However, reelin expression was not altered in the tFgfr 1 
A
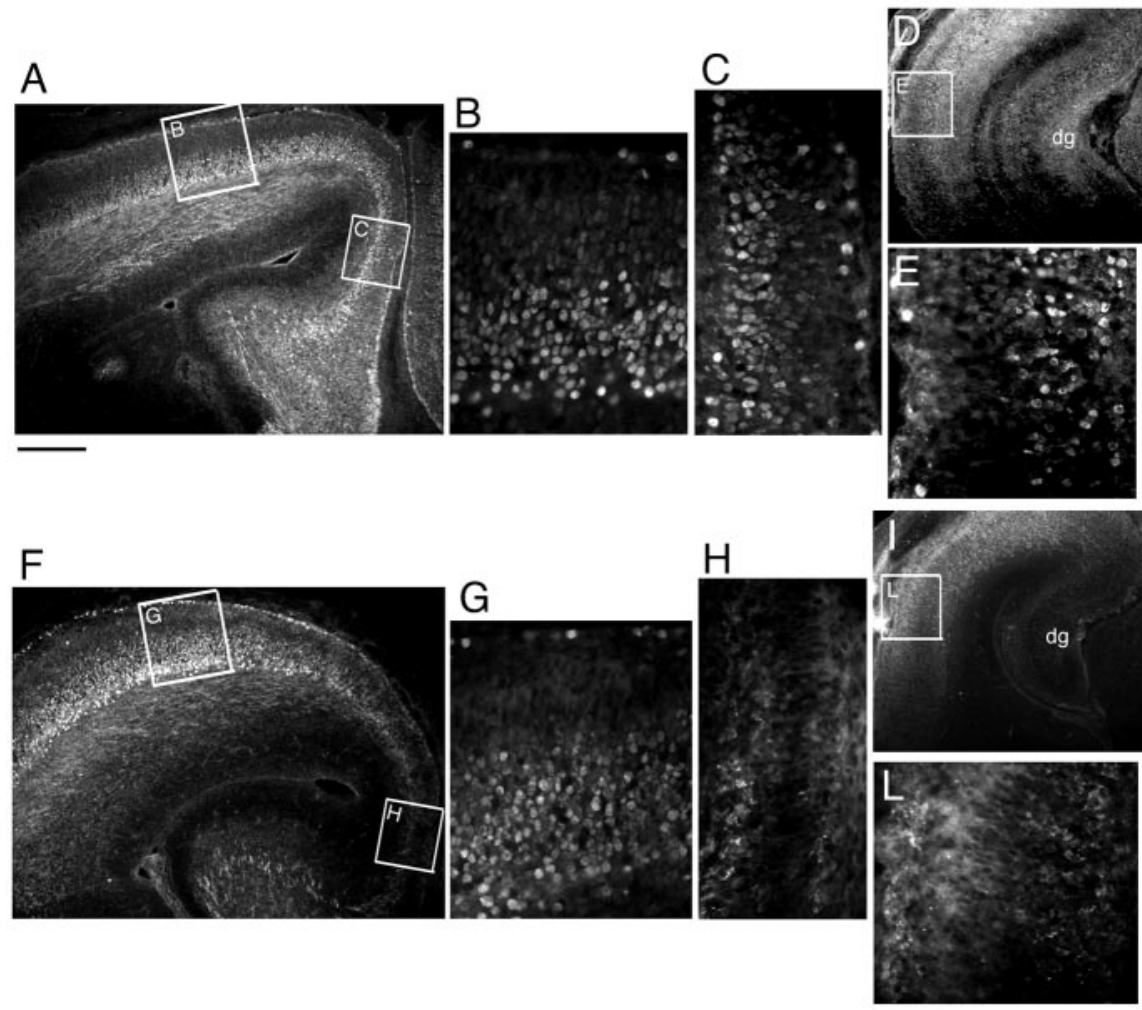

Figure 7. Decrease in Tbr1 expression in neuronal nuclei within the prospective medial prefrontal and temporal cortical areas at $E 18.5$. $A-E$, Wild type; $F-L$, tFgfr1. $A-C, F-H$, Frontal regions; $D, E, I-L$, temporal regions. Note the absence of discrete nuclear staining in the mutant medial prefrontal $(H)$ and temporal cortical regions $(L)$ as compared with the corresponding medial prefrontal $(C$ and temporal $(E)$ regions of wild-type mice. In contrast, nuclear TBR1 staining is fairly normal in more lateral frontal regions of mutant mice $(B, G)$. Dorsal is to the top and medial is to the right in all figures. $\mathrm{dg}$, Dentate gyrus. Scale bars: $A, D, F, I$, $200 \mu \mathrm{m} ; B, C, E, G, H, L, 50 \mu \mathrm{m}$.

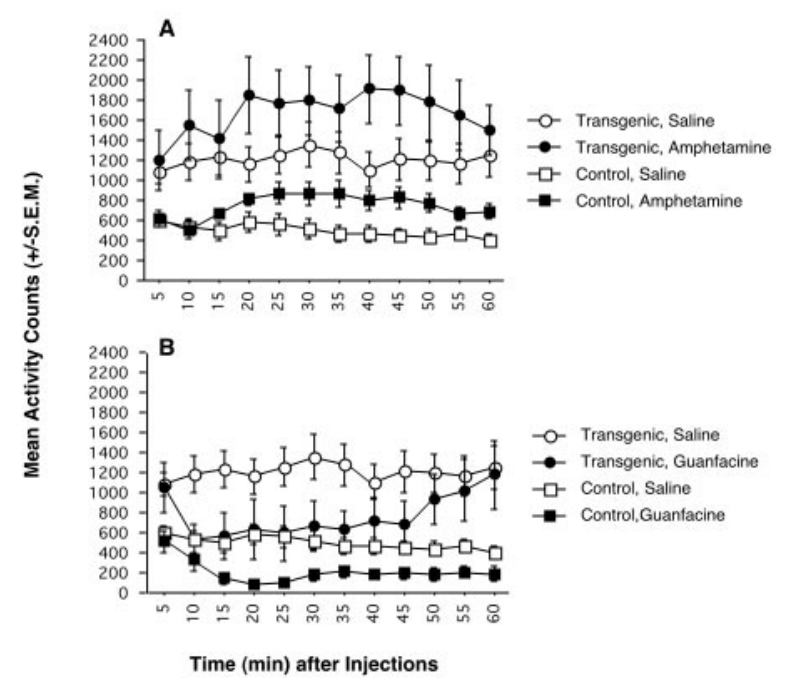

Figure 8. Locomotor activity is increased in transgenic tFgfr1 mice as compared with littermate control animals. Activity counts are expressed as the mean ( \pm SEM) number of photocell beam brakes and are shown for $60 \mathrm{~min}$ at 5 min intervals after injection. There were $8-18$ mice per group depending on condition. $A$, Transgenic tFgfr1 mice displayed marked increases in locomotor activity compared with control animals under baseline conditions (saline). Amphetamine, at a moderate dose $(2.0 \mathrm{mg} / \mathrm{kg})$, increased locomotor activity in both transgenic and control animals relative to saline injections. Activity rates were markedly increased but transiently in tFgfr1 mice. $B$, Conversely, the selective $\alpha 2 \mathrm{~A}$ adrenergic receptor agonist guanfacine $(1.0 \mathrm{mg} / \mathrm{kg})$ reduced locomotor activity rates in both transgenic and control animals. Although activity rates in tFgfr1 mice were normalized by guanfacine, this effect was transient and eventually was not different from transgenic animals given saline. transgenic mice, suggesting that the disruption of FGFR signaling did not disturb the genesis or differentiation of CajalRetzius cells. MAP2 immunostaining performed at E18.5 revealed that the subplate formed normally, even in the presumptive frontal and temporal cortical regions (data not shown). Together, the early events of corticogenesis seemed to have occurred normally in transgenic animals as the PPL was split into the marginal zone and the subplate, with the cortical plate placed in between.

The most striking abnormality in the tFgfr 1 mice was atrophy of the anterior and lateral regions of the cerebral cortex, which is attributable to a decrease in the number of pyramidal cells, particularly in layer 5/6, with resulting collapse of cortical laminas. These region-specific abnormalities were severe enough to cause an overall $50 \%$ decrease in TBR1-expressing pyramidal cells as well as a $40 \%$ decrease in total cortical volume and cell number. Examination of the adult brains revealed that the residual pyramidal neurons were aberrantly placed and had deformed apical dendrites. The phenotype of tFgfr $1 \mathrm{mu}$ tants was primarily restricted to the pyramidal cell lineage. GABAergic interneurons are generated mostly in the basal ganglia, a region that did not express tFgfr1, and reach the cerebral cortex by tangential migration (Anderson et al., 1997; Lavdas et al., 1999). The fact that the number of cortical GABAergic interneurons was unchanged suggests that the migration of these cells was unaffected by the abnormal development of pyramidal cells.

Our findings suggest two molecular mechanisms by which fewer numbers of abnormally positioned pyramidal neurons were generated in $\mathrm{tFgfr} 1$ transgenic mice. The first mechanism is a dysgenesis of radial glial progenitor cells, and the second is a lack of nuclear TBR1 in neurons of the deep layers of the cortical plate. Radial glia are dividing neural progenitor cells extending one endfoot to the ventricle and a radial process to the pia (Kriegstein and Gotz, 2003). In the cortex, $80 \%$ of the radial glia progeny become glutamatergic projection neurons, and $6 \%$ become neurons containing calcium-binding proteins, whereas the remaining 14\% mature to be glia (Malatesta et al., 2003). On the basis of these cell fate studies, the substantial loss of projection neurons may have resulted from the fact that radial glia were fewer in number in the prefrontal and temporal regions of the $\mathrm{CP}$ because of an attenuation of FGFR signaling. The loss of radial glial processes in the embryonic neuroepithelium of Otx1-tFgfr 1 mice was preceded by a decrease in thickness of the $\mathrm{VZ}$ at earlier stages of development with a localized loss in number of progenitor cells in the absence of any changes in cell death. These results suggest that FGFR signaling may be necessary for radial glial cell genesis from earlier neuroepithelial cells. This particular hypothesis is very tantalizing to formulate because both FGFR1 and FGFR2 are expressed by radial glia, and FGFR1 signaling may be required for normal radial glial cell proliferation in the hippocampal primordium (Ohkubo et al., 2004). MAPK (mitogen- 
activated protein kinase)-ERK (extracellular signal-regulated kinase), an intracellular kinase activated by FGFR1 in vitro (Kouhara et al., 1997; LaVallee et al., 1998), is present in its active form in radial glial cells and is activated by FGF2 and FGF8 in cortical explants (Ohkubo et al., 2004). It is possible that MAPK activation regulates radial glial cell division or the outgrowth of radial processes. Because migrating pyramidal cells climb on radial glial processes during their migration to the cortical plate (Rakic, 1988), it is possible that defective radial glia fibers disturb the positioning of pyramidal neurons and secondarily disrupt cortical laminar organization. In summary, the present data suggest that the dysgenesis of glutamatergic neurons in the cortex is a result of disrupted FGFR signaling in radial glial progenitor cells.

A second mechanism for cortical pyramidal neuron dysgenesis in tFgfr 1 embryos is that FGFR1 signaling may be directly or indirectly involved in the correct intracellular targeting of TBR1, because this transcription factor was unable to translocate to the nuclear compartment in the affected regions of the mutant cerebral cortex. The failure to express TBR1 may cause abnormalities in the differentiation of cortical pyramidal neurons. The TBR1 transcription factor is expressed by glutamatergic neurons, the progeny of cortical radial glia, but not by GABAergic neurons or glial cells (Hevner et al., 2001). Radial glial development does not require TBR1 (Hevner et al., 2001), suggesting that aberrant radial glia noted in tFgfr 1 mutants is not a result of TBR1 downregulation. Together, in tFgfr1 mice, two molecular events may be responsible for the decreased number of glutamatergic neurons in frontotemporal cortical areas, reduced number of radial glial cells, and downregulation of TBR1 within their progeny, the pyramidal neurons. Whether Tbr1 is a downstream target of the FGFR signaling pathway in young neurons or whether FGFR1 signaling is required in radial glia for the differentiation of TBR1positive neurons is not yet known.

It has been suggested previously that FGFR signaling regulates process outgrowth in neurons by interacting with neural cell adhesion molecules (NCAMs) or the cadherins (Doherty and Walsh, 1966; Williams et al., 1994; Saffel et al., 1997; Niethammer et al., 2002). NCAM and its homologs bind the extracellular region of FGFR1, causing the activation of PLC $\gamma$ and arachidonic acid release, which in turn activates the phosphorylation of the growth cone molecule GAP43 (Meiri et al., 1998). The Otx1 promoter driving the tFgfr 1 transgene is active within layer 5 cortical pyramidal cells (Frantz et al., 1994). The dysgenesis of apical dendrites of pyramidal neurons in the frontal and temporal areas of tFgfr 1 transgenic mice provides some evidence for a possible role of FGFR signaling in dendritic outgrowth in vivo.

Studies have shown that dominant negative constructs that are soluble have stronger and more widespread effects, possibly attributable to trapping of ligands in the extracellular space (Celli et al., 1998). In contrast, our transmembrane tFgfr 1 construct is likely to produce only a partial inhibition of FGF signaling. For example, the Cre-mediated deletion of Fgfrl in the dorsomedial VZ produces hippocampal atrophy (Ohkubo et al., 2004). Hippocampal atrophy was not observed in our dominant negative tFgfr 1 mutants, likely because tFgfr 1 transgenics may have levels of FGFR1 signaling that are sufficient for hippocampal development. An important question relates to the specificity of the disruption in signaling with respect to different FGF ligands and receptors. The alterations of cortical development present in Otx1-tFgfr1 transgenic mice were not detected after the isolated disruption of the Fgfrl gene in the forebrain neuroepithelium (Hebert et al., 2003). Our results may be explained by a combined attenuation of the function of multiple FGFR. Consistently, a truncated Fgfr1-IIIc construct similar to that used in our studies blocked signaling through the FGFR1, FGFR2 (IIIb and IIIc), and FGFR3 proteins in Xenopus oocytes (Amaya et al., 1991; Ueno et al., 1992). However, the dominant negative blockade may depend on the endogenous and truncate receptors binding the same ligand (Celli et al., 1998). If this is correct, the tFgfr 1 should block the action of FGF1, FGF2, and FGF6, which bind FGFR1, but minimally that of FGF7 or FGF8, which bind FGFR1 poorly. Indeed, there is similarity between the phenotype of Otx1-tFgfr 1 transgenic mice and that of Fgf2 knock-out mice, in that Fgf2 knock-out mice have a decreased density of pyramidal neurons that spares posterior regions of the cerebral cortex (Raballo et al., 2000; Korada et al., 2002). In conclusion, if in vitro binding studies are applicable in vivo, this information suggests that the phenotype of $\mathrm{tFgfr} 1$ transgenic mice may be explained by the attenuation of function of the FGF2-FGFR1-FGFR2 signaling pathways.

However, ligand-binding specificity in vitro may differ from that in vivo. For example, the disruption of the Fgfrl gene in the midbrain was shown to impair isthmic FGF8 signaling (Trokovic et al., 2003). Interfering with the FGF8 pathway in the forebrain markedly alters early cortical patterning (Fukuchi-Shimogori and Grove, 2001; Garel et al., 2003). The relative late emergence of the cortical phenotype observed in tFgfrl transgenics makes it unlikely that the FGF8-FGFR3 pathway is significantly affected, yet we cannot completely exclude that the region-specific defects described here are associated with defects in cortical area map similar to those present in conditional Fgf8 loss-of-function mice or in mice expressing a dominant negative Fgfr3 construct (Fukuchi-Shimogori and Grove, 2001, 2003; Garel et al., 2003). Additional experiments using markers for cortical area boundaries are necessary to determine whether the patterning of the cerebral cortex is altered in tFgfr1 mutants.

The region-specific effects of disrupted FGFR signaling suggest that some regions of the cortical neuroepithelium require a higher level of FGFR signaling. These malformations were not attributable to unequal expression pattern of the Otx1-tFgfr1 transgene; rather, we suggest that the selective distribution of FGF ligands is responsible. In this respect, it is intriguing that the areas where strongest cortical aberrations were noted in the tFgfr 1 transgenic mice are adjacent to two FGF-expressing signaling centers, the dorsoanterior midline and the "cortical antihem" at the lateral edge of the cortical neuroepithelium (Meyers et al., 1998; Assimacopoulos et al., 2003).

The most intriguing aspect of the tFgfr 1 transgenic mice is the apparent association between cortical defects and hyperactive behavior. Locomotor hyperactivity has been observed after developmental or drug-induced alterations in subcortical dopaminergic, noradrenergic, and cholinergic systems (Trovero et al., 1992; Blanc et al., 1994; Gerber et al., 2001; Zhuang et al., 2001). Yet, we have no anatomical evidence that any of these systems is altered in tFgfr 1 mice. Furthermore, the ability of amphetamine to further increase activity in the transgenic animals and that of guanfacine to attenuate the hyperactive behavior suggests that these subcortical systems were functionally intact. It is possible that the loss of cortical pyramidal neurons in frontal and temporal areas observed in the tFgfrl transgenic mice may be linked directly or indirectly to the locomotor hyperactivity. Although we have as yet no direct proof supporting the hypothesis that the glutamatergic neuron loss is the reason for hyperactivity, it is interesting that locomotor hyperactivity is present in mice with NMDA receptor hypofunction (Mohn et al., 1999; Miyamoto et al., 2001; 
Ballard et al., 2002), and that in hyperactive mice lacking the dopamine transporter, glutamate receptor antagonists both worsen the hyperactivity and prevent the inhibitory effect of psychostimulants and serotonergic drugs on hyperactive locomotor behavior (Gainetdinov et al., 2001).

Our tFgfr1 mice provide the first in vivo evidence that developmental defects caused by an attenuation of FGFR signaling are associated with robust spontaneous hyperactivity that develops during the juvenile stage and persists into adulthood. Guanfacine has been reported to be beneficial for reducing tic severity in patients with Tourette's syndrome and impulsivity or hyperactivity in children with attention-deficit hyperactivity disorder (Scahill et al., 2001). The observation that our mice also respond to guanfacine suggests that these mice may model aspects of these disorders and may provide an avenue to better understand the developmental defects underlying disorders of inhibitory control.

\section{References}

Amaya E, Musci TJ, Kirschner MW (1991) Expression of a dominant negative mutant of the FGF receptor disrupts mesoderm formation in Xenopus embryos. Cell 66:257-270.

Anderson SA, Eisenstat DD, Shi L, Rubenstein JL (1997) Interneuron migration from basal forebrain to neocortex: dependence on Dlx genes. Science 278:474-476.

Anton ES, Marchionni MA, Lee KF, Rakic P (1997) Role of GGF/neuregulin signaling in interactions between migrating neurons and radial glia in the developing cerebral cortex. Development 124:3501-3510.

Assimacopoulos S, Grove EA, Ragsdale CW (2003) Identification of a Pax6dependent epidermal growth factor family signaling source at the lateral edge of the embryonic cerebral cortex. J Neurosci 23:6399-6403.

Ballard TM, Pauly-Evers M, Higgins GA, Ouagazzal AM, Mutel V, Borroni E, Kemp JA, Bluethmann H, Kew JN (2002) Severe impairment of NMDA receptor function in mice carrying targeted point mutations in the glycine binding site results in drug-resistant nonhabituating hyperactivity. J Neurosci 22:6713-6723.

Blanc G, Trovero F, Vezina P, Herve D, Godeheu AM, Glowinski J, Tassin JP (1994) Blockade of prefronto-cortical alpha 1-adrenergic receptors prevents locomotor hyperactivity induced by subcortical D-amphetamine injection. Eur J Neurosci 6:293-298.

Campbell MJ, Hof PR, Morrison JH (1991) A subpopulation of corticocortical neurons is distinguished by somatodendritic distribution of neurofilament protein. Brain Res 539:133-136.

Caviness Jr VS (1982) Neocortical histogenesis in normal and reeler mice: a developmental study based upon $\left[{ }^{3} \mathrm{H}\right]$ thymidine autoradiography. Brain Res Dev Brain Res 4:293-302.

Celli G, LaRochelle WJ, Mackem S, Sharp R, Merlino G (1998) Soluble dominant-negative receptor uncovers essential roles for fibroblast growth factors in multi-organ induction and patterning. EMBO J 17:1642-1655.

Chellaiah A, Yuan W, Chellaiah M, Ornitz D (1999) Mapping ligand binding domains in chimeric fibroblast growth factor receptor molecules. J Biol Chem 274:34785-34794.

Cruikshank SJ, Killackey HP, Metherate R (2001) Parvalbumin and calbindin are differentially distributed within primary and secondary subregions of the mouse auditory forebrain. Neuroscience 105:553-569.

D’Arcangelo G, Miao GG, Chen S-C, Soares HD, Morgan JI, Curran T (1995) A protein related to extracellular matrix proteins deleted in the mouse reeler. Nature 374:719-723.

Deng C-X, Wynshaw-Boris A, Shen MM, Daugherty C, Ornitz DM, Leder P (1994) Murine FGFR-1 is required for early postimplantation growth and axial organization. Genes Dev 8:3045-3057.

Doherty P, Walsh FS (1966) A model for axonal growth. Mol Cell Neurosci 8:99-111.

Feng L, Hatten ME, Heintz N (1994) Brain lipid-binding protein (BLBP): a novel signaling system in the developing mammalian CNS. Neuron 12:895-908.

Franklin KBJ, Paxinos G (1997) The mouse brain in stereotaxic coordinates. San Diego: Academic.

Franowicz JS, Kessler LE, Borja CM, Kobilka BK, Limbird LE, Arnsten AF (2002) Mutation of the alpha2A-adrenoceptor impairs working memory performance and annuls cognitive enhancement by guanfacine. J Neurosci 22:8771-8777.

Frantz GD, Weimann JM, Levin ME, McConnell SK (1994) Otx1 and Otx2 define layers and regions in developing cerebral cortex and cerebellum. J Neurosci 14:5725-5740.

Fukuchi-Shimogori T, Grove EA (2001) Neocortex patterning by the secreted signaling molecule FGF8. Science 294:1071-1074.

Fukuchi-Shimogori T, Grove EA (2003) Emx2 patterns the neocortex by regulating FGF positional signaling. Nat Neurosci 6:825-831.

Gainetdinov RR, Mohn AR, Bohn LM, Caron MG (2001) Glutamatergic modulation of hyperactivity in mice lacking the dopamine transporter Proc Natl Acad Sci USA 98:11047-11054.

Garel S, Huffman KJ, Rubenstein JLR (2003) Molecular regionalization of the neocortex is disrupted in Fgf8 hypomorphic mutants. Development 130:1903-1914.

Gerber DJ, Sotnikova TD, Gainetdinov RR, Huang SY, Caron MG, Tonegawa S (2001) Hyperactivity, elevated dopaminergic transmission, and response to amphetamine in M1 muscarinic acetylcholine receptordeficient mice. Proc Natl Acad Sci USA 98:15312-15317.

Hartfuss E, Galli R, Heins N, Gotz M (2001) Characterization of CNS precursors subtypes and radial glia. Dev Biol 229:15-30.

Hebert JM, Lin M, Partanen J, Rossant J, McConnell SK (2003) FGF signaling through FGFR1 is required for olfactory bulb morphogenesis. Development 15:1101-1111.

Hevner RF, Shi L, Justice N, Hsueh Y, Sheng M, Smiga S, Bulfone A, Goffinet AM, Campagnoni AT, Rubenstein JL (2001) Tbrl regulates differentiation of the preplate and layer 6. Neuron 29:353-366.

Korada S, Zheng W, Basilico C, Schwartz ML, Vaccarino FM (2002) Fgf2 is necessary for the growth of glutamate projection neurons in the anterior neocortex. J Neurosci 22:863-875.

Kouhara H, Hadari YR, Spivak-Kroizman T, Schilling J, Bar-Sagi D, Lax I, Schlessinger J (1997) A lipid-anchored Grb2-binding protein that likns FGF-receptor activation to the Ras/MAPK signaling pathway. Cell 89:693-702.

Kriegstein AR, Gotz M (2003) Radial glia diversity: a matter of cell fate. Glia 43:37-43.

LaVallee TM, Prudovsky IA, McMahon GA, Hu X, Maciag T (1998) Activation of the MAP kinase pathway by FGF-1 correlates with cell proliferation induction while activation of the Src pathway correlates with cell migration. J Cell Biol 141:1647-1658.

Lavdas AA, Grigoriou M, Pachnis V, Parnavelas JG (1999) The medial ganglionic eminence gives rise to a population of early neurons in the developing cerebral cortex. J Neurosci 19:7881-7888.

Luskin MB, Shatz CJ (1985) Studies of the earliest generated cells of the cat's visual cortex: cogeneration of subplate and marginal zones. J Neurosci 5:1062-1075.

Malatesta P, Harfuss E, Gotz M (2000) Isolation of radial glial cells by fluorescent-activated cell sorting reveals a neuronal lineage. Development 127:5253-5263.

Malatesta P, Hack MA, Hartfuss E, Kettenmann H, Klinkert W, Kirchnoff F, Gotz M (2003) Neuronal or glial progeny: regional differences in radial glia fate. Neuron 37:751-764.

Marin-Padilla M (1998) Cajal-Retzius cells and the development of the neocortex. Trends Neurosci 21:64-71.

Meiri KF, Saffell JL, Walsh FS, Doherty P (1998) Neurite outgrowth stimulated by neural cell adhesion molecules requires growth-associated protein-43 (GAP-43) function and is associated with GAP-43 phosphorylation in growth cones. J Neurosci 18:10429-10437.

Meyers EN, Lewandoski M, Martin GR (1998) An Fgf8 mutant allelic series generated by Cre- and Flp-mediated recombination. Nat Genet 18:136-141.

Misson JP, Edwards MA, Yamamoto M, Caviness Jr VS (1988) Identification of radial glial cells within the developing murine central nervous system: studies based upon a new immunohistochemical marker. Brain Res Dev Brain Res 44:95-108.

Miyamoto Y, Yamada K, Noda Y, Mori H, Mishina M, Nabeshima T (2001) Hyperfunction of dopaminergic and serotonergic neuronal systems in mice lacking the NMDA receptor epsilon1 subunit. J Neurosci 21: $750-757$.

Mohn AR, Gainetdinov RR, Caron MG, Koller BH (1999) Mice with reduced NMDA receptor expression display behavior related to schizophrenia. Cell 98:427-436. 
Niethammer P, Delling M, Sytnyk V, Dityatev A, Fukami K, Schachner M (2002) Cosignaling of NCAM via lipid rafts and the FGF receptor is required for neuritogenesis. J Cell Biol 157:521-532.

Noctor SC, Flint AC, Weissman TA, Dammerman RS, Kriegstein AR (2001) Neurons derived from radial glial cells establish radial units in neocortex. Nature 409:714-720.

Ohkubo Y, Uchida AO, Shin D, Partanen J, Vaccarino FM (2003) FGFR1 is essential for regulation of radial glia proliferation in hippocampal development. Soc Neurosci Abstr 29:136.6.

Ornitz D, Itoh N (2001) Fibroblast growth factors. Gen Biol 2:3005-3012.

Ornitz DM, Xu J, Colvin JS, McEwen DG, MacArthur CA, Coulier F, Gao G, Goldfarb M (1996) Receptor specificity of the fibroblast growth factor family. J Biol Chem 271:15292-15297.

Raballo R, Rhee J, Lyn-Cook R, Leckman JF, Schwartz ML, Vaccarino FM (2000) Basic fibroblast growth factor (Fgf2) is necessary for cell proliferation and neurogenesis in the developing cerebral cortex. J Neurosci 20:5012-5023.

Ragsdale CW, Grove EA (2001) Patterning the mammalian cerebral cortex. Curr Opin Neurobiol 11:50-58.

Rakic P (1988) Specification of cerebral cortical areas. Science 241:170-176.

Robinson ML, MacMillan-Crow LA, Thompson JA, Overbeek PA (1995) Expression of a truncated FGF receptor results in defective lens development in transgenic mice. Development 121:3959-3967.

Rousselot P, Heintz N, Nottebohm F (1997) Expression of brain lipid binding protein in the brain of the adult canary and its implications for adult neurogenesis. J Comp Neurol 385:415-426.

Saffel JL, Williams EJ, Mason IJ, Walsh FS, Doherty P (1997) Expression of a dominant negative FGF receptor inhibits axonal growth and FGF receptor phosphorylation stimulated by CAMs. Neuron 18:231-242.

Scahill L, Chappel PB, Kim YS, Schultz RT, Katsovich L, Sheperd E, Arnsten AF, Cohen DJ, Leckman JF (2001) A placebo-controlled study of guanfacine in the treatment of children with tic disorders and attention-deficit hyperactivity disorder. Am J Psychiatry 158:1067-1074.

Shashikant CS, Bieberich CJ, Belting H-G, Wang JCH, Borbely MA, Ruddle FH (1995) Regulation of Hoxc-8 during mouse embryonic development: identification and characterization of critical elements involved in early neural tube expression. Development 121:4339-4347.

Shibata T, Yamada K, Watanabe M, Ikenaka K, Wada K, Tanaka K, Inoue Y (1997) Glutamate transporter GLAST is expressed in the radial gliaastrocyte lineage of developing mouse spinal cord. J Neurosci 17:9212-9219.
Simeone A, Acampora D, Mallamaci A, Stornaiuolo A, D’Apice MR, Nigro V, Boncinelli E (1993) A vertebrate gene related to orthodenticle contains a homeodomain of the bicoid class and demarcates anterior neuroectoderm in the gastrulating mouse embryo. EMBO J 12:2735-2747.

Takahashi T, Nowakowski RS, Caviness VS (1993) Cell cycle parameters and patterns of nuclear movement in the neocortical proliferative zone of the fetal mouse. J Neurosci 13:820-833.

Trokovic R, Trokovic N, Hernesniemi S, Pirvola U, Vogt Weisenhorn DM, Rossant J, McMahon AP, Wurst W, Partanen J (2003) FGFR1 is independently required both in developing mid- and hindbrain for sustained response to isthmic signals. EMBO J 22:1-13.

Trovero F, Blanc G, Herve D, Vezina P, Glowinski J, Tassin JP (1992) Contribution of an alpha 1-adrenergic receptor subtype to the expression of the "ventral tegmental area syndrome." Neuroscience 47:69-76.

Ueno H, Gunn M, Dell K, Tseng A, Williams L (1992) A truncated form of fibroblast growth factor receptor 1 inhibits signal transduction by multiple types of fibroblast growth factor receptor. J Biol Chem 267:1470-1476.

Vaccarino FM, Schwartz ML, Raballo R, Nilsen J, Rhee J, Zhou M, Doetschman T, Coffin JD, Wyland JJ, Hung Y-TE (1999) Changes in cerebral cortex size are governed by fibroblast growth factor during embryogenesis. Nat Neurosci 2:246-253.

Wang Q, Bardgett ME, Wong M, Wozniak DF, Lou J, McNeil BD, Chen C, Nardi A, Reid DC, Yamada K, Ornitz DM (2002) Ataxia and paroxysmal dyskinesia in mice lacking axonally transported FGF14. Neuron 35:25-38.

Werner S, Weinberg W, Liao X, Peters KG, Blessing M, Yuspa SH, Weiner RL, Williams LT (1993) Targeted expression of a dominant-negative FGF receptor mutant in the epidermis of transgenic mice reveals a role of FGF in keratinocyte organization and differentiation. EMBO J 12:2635-2643.

Wilkinson DG, Nieto MA (1993) Detection of messenger RNA by in situ hybridization to tissue sections and whole mounts. Methods Enzymol 225:361-373.

Williams EJ, Walsh FS, Doherty P (1994) Tyrosine kinase inhibitors can differentially inhibit integrin-dependent can CAM-stimulated neurite outgrowth. J Cell Biol 124:1029-1037.

Yamaguchi TP, Harpal K, Henkemeyer M, Rossant J (1994) fgfr-1 is required for embryonic growth and mesodermal patterning during mouse gastrulation. Genes Dev 8:3032-3044.

Zhuang X, Oosting RS, Jones SR, Gainetdinov RR, Miller GW, Caron MG, Hen R (2001) Hyperactivity and impaired response habituation in hyperdopaminergic mice. Proc Natl Acad Sci USA 98:1982-1987. 